\title{
Inhibitor of adaptor protein shows self-antigen selectivity
}

\begin{tabular}{|c|c|}
\hline $\begin{array}{l}\text { the } \\
\text { therapeutic } \\
\text { effect of } \\
\text { AX-024 } \\
\text { persisted } \\
\text { even after the } \\
\text { treatment was } \\
\text { discontinued }\end{array}$ & $\begin{array}{l}\text { Patients suffering from autoimmune } \\
\text { diseases are usually treated with } \\
\text { immunosuppressive drugs, leaving } \\
\text { them prone to infection. Now, } \\
\text { reporting in Science Translational } \\
\text { Medicine, Alarcon and colleagues } \\
\text { show that a small molecule inhibitor } \\
\text { of the adaptor protein NCK, which } \\
\text { acts downstream of the T cell } \\
\text { receptor (TCR), is highly potent in } \\
\text { different models of autoimmune con- } \\
\text { ditions, without affecting immune } \\
\text { responses to infectious agents. } \\
\text { NCK is a modular adaptor } \\
\text { protein that connects different } \\
\text { transmembrane receptors to multiple } \\
\text { intracellular signalling pathways } \\
\text { and is a crucial regulator of the actin }\end{array}$ \\
\hline
\end{tabular}

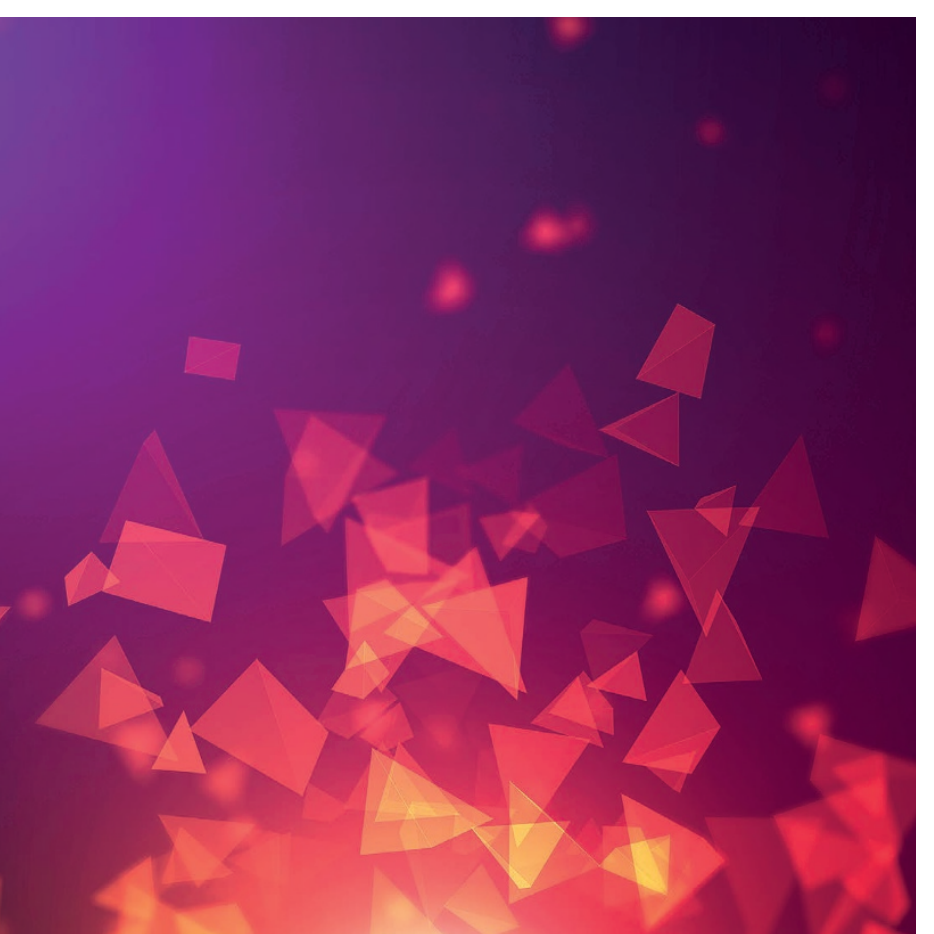

Raki Halder/Alamy Stock Photo cytoskeleton. In mature T cells, antigen stimulation triggers the recruitment of NCK to the TCR an interaction that is particularly important for TCR signalling in response to weak antigens.

Using virtual screening and combinatorial chemistry, the authors developed AX-024, an orally available low-molecular weight compound that binds to an uncommon amino acid pocket in the amino-terminal SH3 domain of NCK and specifically inhibits its interaction with the cytoplasmic tail of the TCR subunit $\mathrm{CD} 3 \varepsilon$. In vitro, $\mathrm{AX}-024$ potently inhibited the release of cytokines by $\mathrm{T}$ cells in response to anti-CD3mediated TCR stimulation, but did not seem to disrupt other cellular functions of NCK.

In vivo experiments in mice and rats demonstrated that AX-024, administered orally or by intraperitoneal injection, was well tolerated, even at high doses. In the mouse model of imiquimod-induced psoriasis, daily oral treatment with AX-024 significantly reduced skin thickening and attenuated psoriasislike symptoms of inflammation. In the ovalbumin-antigen-induced asthma model, it prevented allergic airway sensitization, and in the experimental autoimmune encephalomyelitis model of multiple sclerosis (MS), treatment with AX-024 was more effective than current MS drugs such as glatiramer acetate and cladribine. Even when treatment was delayed until the onset of neurological symptoms, AX-024 had therapeutic efficacy. This was comparable to treatment with the MS drug fingolimod (albeit with slightly slower kinetics). However, in contrast to fingolimod, the therapeutic effect of AX-024 persisted even after the treatment was discontinued.

Further ex vivo and in vivo experiments indicated that AX-024, by altering the quality and/or strength of the TCR signal, promotes differentiation of $\mathrm{CD}^{+}$effector cells towards antiinflammatory $\mathrm{CD} 4^{+} \mathrm{T}$ cell subsets and FOXP $3{ }^{+} \mathrm{CD} 4^{+}$regulatory T cells providing an explanation for the lasting effects of the drug. Surprisingly, treatment with AX-024 did not impair the generation of protective memory $T$ cell responses after vaccination with a poxviral $\mathrm{CD}^{+} \mathrm{T}$ cell epitope, and it did not affect survival rates after viral challenge with ectromelia virus, which causes mousepox.

The authors point out that the mechanism of selectivity for selfantigens versus pathogen-derived antigens is not completely understood but may lie in the differential requirement for NCK recruitment to the TCR in response to weak versus strong antigens. As AX-024 directly interferes with TCR signalling, it is an attractive candidate as a broadspectrum agent for autoimmune and inflammatory conditions. It is first-in-class for both targeting an SH3 domain and for directly inhibiting TCR signals and has passed phase Ia/Ib clinical trials.

Alexandra Flemming

ORIGINAL ARTICLE Borroto, A. et al. First-inclass inhibitor of the T cell receptor for the treatment of autoimmune disease. Sci. Transl Med. 8, 370ra184 (2016) 